\title{
Nelson Goodman's Autographic-Allographic Distinction in Architecture: The Case of Mies van der Rohe's Barcelona Pavilion
}

\begin{abstract}
In Languages of Art, Nelson Goodman proposes the categories of the autographic and the allographic to philosophically distinguish between an original work and its copy, reproduction, or forgery. However clear these distinctions might be in cases such as painting or music, difficulties arise when dealing with architecture, for our judgments regarding the identity of an architectural work cannot be indisputably classified according to Goodman's categories. Thus, first, I will discuss the scope of Goodman's autographic and allographic criteria to identify an architectural work. Second, I will examine the specific case of Mies van der Rohe's Barcelona Pavilion, first built in 1929 and reconstructed in 1986, to show how the allographic and the autographic are inextricably linked when establishing the identity of architectural works. Furthermore, I will argue that Goodman's statements on the identity status of architecture need to be reconsidered.
\end{abstract}

\section{The Identity of Architectural Works: the Autographic and the Allographic}

In the chapter entitled "Art and Authenticity" ( $L A, 99-123)$, Goodman develops the distinction between autographic and allographic arts based on the observation that some works of art cannot be faked. While it is possible to have a perfect copy of a painting, no forgery of a known musical piece can be made. ${ }^{1}$ In Goodman's words:

A work of art [is] autographic if and only if the distinction between original and forgery of it is significant; or better, if and only if even the most exact duplication of it does not thereby count as genuine. If a work of art is autographic, we may also call that art autographic. Thus painting is autographic, music nonautographic, or allographic $(L A, 113)$.

\footnotetext{
${ }^{1}$ It is theoretically possible to forge an unknown musical work by using allographic processes, as it is argued in the following articles, based on Goodman's philosophy: (Kivy 2000, 2002) and (Pillow 2002).
} 
Hence, the autographic identifies a category of works that cannot be replicated, i.e., every difference between a work and even its closest copy makes a difference to the work's identity. The history of production is the criterion for establishing the identity of an autographic work and what allows us to discriminate between the original and something else. The autographic does not mean singularity, for there are autographic and multiple works, such as engravings and cast sculptures. That is to say, an artistic discipline is autographic if the identification of the works in this discipline necessarily depends on the history of production; this is not related to singularity or multiplicity. ${ }^{2}$

By contrast, the allographic identifies a category of works that can be replicated, i.e., the difference between an original and its duplication is irrelevant. The criteria for establishing the identity of allographic works are a notational scheme or a notational system, which allow us to affirm that pieces sharing certain determinate and identifiable characteristics are the same work. This implies that allographic works are potentially multiple and reproducible; there can be several instances of the same allographic work. Although these works of art also have histories of production, this is not the criterion for defining the work as it is; music, literature, and performing arts are allographic, for, despite having a history of production, a score, a text, or a script are needed to identify a work as such $(L A, 122$; $M M, 140)$.

According to Goodman, the primary logical function of a notational scheme and a notational system is to identify a work, even though it has other functions such as being a "practical aid to production" $(L A, 128)$. In order to fulfill its allographic identificatory function, every notational system has to accomplish certain syntactic and semantic requirements, whereas a notational scheme must only fulfill the syntactic requirements (LA, 130-141; 148-154). In general, music, literature, and dance are allographic arts, although there are some exceptions: music with no score, such as jazz improvisations, is autographic; however, since it is possible to actually create a notational system that fixes their identities, they can be taken as allographic too. In opposition, painting, etchings, and sculpture

2 As Goodman affirms: "Concerning the distinction between autographic and allographic arts or works, the first point is that this distinction does not coincide with that between singular and multiple arts; for some multiple arts, such as etching, are autographic" (MM, 140). 
are usually autographic. ${ }^{3}$ And architecture, according to Goodman, can be classified under both categories: ${ }^{4}$

We are not as comfortable about identifying an architectural work with a design rather than a building as we are about identifying a musical work with a composition rather than a performance. In that architecture has a reasonably appropriate notational system and that some of its works are unmistakably allographic, the art is allographic. But insofar as its notational language has not yet acquired full authority to divorce identity of work in all cases from particular production, architecture is a mixed and transitional case $(L A, 221)$.

In this passage, Goodman comments on the hybrid status of architecture as an artistic discipline that is both autographic and allographic, since both criteria for establishing the identity of a work are valid. Some buildings are identified by the history of their productions, while others are identified by means of a notation; moreover, a single building can be judged according to both criteria at the same time. Note that the autographic and the allographic help us clarify and classify our judgments regarding the identity of a work of art, i.e., these criteria are a reflection of our practice of distinguishing the constitutive elements of a work. If we consider a building to be only autographic, it is because important constitutive elements of the building's identity would be lost if considered from the allographic perspective.

This in-between position of architecture is not only synchronic but also diachronic: defining architecture as a "mixed case" means that the autographic and the allographic criteria coexist simultaneously; defining it as a "transitional case" means that the allographic criterion to establish the identity of an architectural work succeeds the autographic, and thus

${ }^{3}$ Some exceptions can also be found in the autographic arts. Kirk Pillow discusses the case of Sol LeWitt, and argues that that Goodman's autographic-allographic distinction does not apply for some of LeWitt's paintings (Pillow, 2003), and Michel Weemans also comments on LeWitt as well as on Claude Rutault's and Lawrence Weiner's works to argue that the allographic criterion is valid in those cases and, hence, painting can be also allographic (Weemans, 2001).

${ }^{4}$ I will take for granted that architecture is or can be considered an art, although not every building is a work of art taking into account Goodman's statement according to which "[a] building is a work of art insofar as it signifies, means, refers, symbolizes in some way" $(R, 33)$. Nevertheless, since also according to Goodman it is possible to make a "work work," i.e., that almost any object can be considered from an aesthetic point of view, then it seems that it is, at least theoretically, always possible to consider a building aesthetically (see: $M M, 174-187$. ) 
presupposes an inherent historical process. This is precisely what Goodman assumes when he states that architecture will become completely allographic once its notational system has "acquired full authority to divorce identity of work in all cases from particular production" $(L A, 221)$. In other words, this affirmation acknowledges that the decisive factor in determining whether architecture is autographic or allographic is the perfection of the correspondent notation, in this case, plans, elevations, and sections.

When discussing architectural plans, Goodman compares them with musical scores, which are the paradigmatic example of notational systems in art. In Languages of Art, Goodman provides two different characterizations of plans as notations: in the first one he considers plans as scores, i.e., as notational systems that fulfill both syntactic and semantic requirements $(L A, 219)$; in the second one, he maintains that plans are as scripts, i.e., notational schemes that only fulfill syntactic requirements ( $L A$, 219). The reason for this shift from system to scheme is that whereas it is possible to construct a building from a set of given plans, it is not possible to derive a unique plan from a given building. That is to say, whereas the semantic requirements are fulfilled in the former case, they are not in the latter. Architecture, then, would function in a way more similar to drama rather than to music, because from the work multiple notational schemes can be created. ${ }^{5}$ In other aspects, however, architecture functions in a way closer to music. For instance, just as a book does constitute a literary work, plans and scores do not constitute architectural and musical works: they are only their notations. Moreover, plans and scores include integral parts that constitute the notation itself, and others that cannot be considered notational. The notations of architecture (e.g., plans, elevations, and sections) result from the combination of accurate drawings and measurements represented to scale, which is parallel to the musical scale system; the non-notational parts of plans are the written specifications or other non-codified indications regarding certain aspects of the building (construction materials, for instance), which are comparable to the verbal specifications of tempo in a score. In a certain sense, the non-notational aspects of plans over-define, as it were, a building insofar as they establish more properties apart from the ones that are strictly constitutive elements,

${ }^{5}$ To determine whether plans are notational systems or notational schemes requires a more thorough discussion that is far beyond of the purposes of this paper. In what follows I will talk about notations in general, without specifying whether they are systems or schemes. 
i.e., that are fixed by a notation that fulfills the syntactic and semantic requirements $(L A, 218-221)$.

Despite these similarities between architectural and musical notations, scores are much more codified than plans, and for this reason Goodman affirms that architecture does not share the entire characteristic features of a mature notation. While musical scores can resort to very precise codifications to establish how every single note has to be played, architectural plans lack a similar system to fix how each and every one of their parts has to be executed. Therefore, extranotational information is (still) required to explicitly state constructive elements such as the wall texture, or the exact color; these are usually exemplified by means of a sample: a piece of a wall with the correspondent definitive surface and color serves as a model for the rest of the building ( $W W, 63-70)$. Since for Goodman architecture will not become absolutely allographic until its notation is able to completely fix the identity of architectural works, it is fundamental to explore whether it is feasible for plans to develop into a perfect notation to include the features now expressed in an extranotational way (acknowledging, of course, that these characteristics are constitutive for the work's identity). This is exactly what Saul Fisher undertakes when he argues, based on Goodman's theory, that Computer Aided Design (CAD) theoretically allows the complete specification of the elements that are part of the architect's extranotational language by means of codification (Fisher, 2000). ${ }^{6}$ In this way, identification of architectural works could be independent of any particular building or, in other words, with the progressive transformation of plans from analogical to digital, the

\footnotetext{
${ }^{6}$ In this article, Fisher not only argues that through CAD it is possible to develop a notational system that fixes the constitutive elements of a building, but also the "expressive" or aesthetic ones. I disagree with this statement, because the role of notational systems is only to identify a work as such and not to uniquely fix its aesthetic properties. First, Fisher should clearly define what an aesthetic property is. Second, the inclusion of aesthetic properties in a notation would have as a consequence that two instances of a same work with different aesthetic properties could not be identified as the same work or with the same notation. As Goodman affirms: "Thus, even where the constitutive properties of a work are clearly distinguished by means of a notation, they cannot be identified with the aesthetic properties" (LA, 120). Apart from confusing constitutive and aesthetic properties, Fisher also mixes up the artist's intentionality and constitutive features of a work and this brings him to limit the range of Goodman's allographic criterion and, to a certain extent, to blur the distintion between the autographic and the allographic.
} 
notational system can potentially become the only criterion to determine the identity of a building.

However, even though a perfect notation could be available, some architectural works resist being considered only from an allographic perspective. As Goodman affirms:

[A]11 houses complying with the plans for Smith-Jones Split-Level \#17 are equally instances of that architectural work. But in the case of an earlier architectural tribute to womanhood, the Taj Mahal, we may bridle at considering another building from the same plans and even on the same site to be an instance of the same work rather than a copy $(L A, 220-221)$.

Although it would be possible to build a copy of the Taj Mahal, the criterion to identify this building is still the history of its construction and not a notation. It is important to note that the fact of not knowing exactly every detail of its history of production does not invalidate the possibility of establishing the work's identity autographically. Moreover, even if we did not possess any information about the history of production of a work, this would not invalidate the autographic criterion. This is the case of anonymous buildings, whose history of production is impossible to trace back and yet these buildings can only be autographically identified.

Apart from stressing that an exact reproduction of the Taj Mahal would only be a copy, the passage by Goodman just cited also implies that the difference between multiple allographic buildings and singular autographic architectural works is related to the distinction between what could be called high and low architecture. ${ }^{7}$ While tract housing sprawls throughout suburban areas and this process has no effect on its identity, no masterpiece of architecture is reproduced without emphasizing that the subsequent instances are not the original but simply replicas (the Parthenon in Nashville's Centennial Park is simply a copy of the one in Athens). ${ }^{8}$ It

${ }^{7}$ Note that it is also possible to have two or more identical, original, and autographic buildings. In that case, it could be considered that the architectural work is composed of two or more buildings, for a copy or a reproduction of this work would mean to construct all of them. This is the case, for instance, of Mies van der Rohe's two Lake Shore Drive Apartments in Chicago, or M.I. Pei three Silver Towers in New York.

${ }^{8}$ I use the term "replica" in the sense of reconstruction, copy, duplicate, or reproduction of a work of art, and not in Goodman's technical sense according to which a work is a replica of another if and only if they are instances of the same work and share the same syntactical properties. This implies that there are only replicas of allographic works that have the same notation (see: $L A, 131-132$ ). 
thus seems that, in general, for buildings aesthetically less valuable, the identity criterion is the allographic, and, for the others, it is the autographic. In other words, there exists a dichotomy between potential reproducibility and actual limitation in the construction of architectural works. ${ }^{9}$

Architecture, thus, has a double nature; it is a "mixed and transitional case" not only because some buildings are considered autographic while at the same time others are taken to be allographic, but also because some of their parts are autographic and others allographic, as would be the case of autographic buildings containing an allographic inscription. Yet architecture can be considered partly autographic and partly allographic from another point of view. According to Goodman, arts can be classified into one-stage and two-stage arts $(L A, 114-115)$. Architecture is a twostage art, because first it is necessary to design a building and then to actually build it, which implies two phases in the construction process. Precisely for this reason, a notation was developed: to assure the correct transition from design to construction in a process in which several people intervene $(L A, 220)$. Architecture can be considered allographic in its first phase and autographic in the second phase. The plan is allographic because its relevant aspect is the accurate reproduction of a series of specifications that fix the identity of a building, and, for this sake, the history of its production is irrelevant; in other words, it does not matter if the plan is the first and original one (if existing) or not. The actual building, which corresponds to the second phase, is autographic, for the history of production is the criterion necessary to distinguish between two buildings that follow the same plan, i.e., the first phase of an architectural work. This is the only way to distinguish between two or more identical works, such

\footnotetext{
${ }^{9}$ Gérard Genette expresses this idea as follows: "The case of architecture may seem paradoxical, because this art, which today possesses systems of (de)notation powerful enough to make possible the indefinite multiplication of its realizations, never exploits this possibility, except in aesthetically least prestigious productions [...]. As to the unique character of works of high fashion (actually, I am told, one realization of each is authorized per continent, whatever that rather hazy geographical term may mean), it stems in part from a deliberate restriction whose motives are obvious, and in part from the autographic nature of this practice - for not only does nothing prevent an art from functioning in one regime in the case of certain of its works, and in the other in the case of certain others; it is also quite possible for one and the same work to be autographic in one of its parts and allographic in another" (Genette 1997, 97).
} 
as the Cinderella Castle built in 1971 in the Walt Disney Resort in Florida and the one built in 1983 for the Tokyo Disney Resort.

Obviously, the distinction among identical works is possible only if sitespecificity is taken as an indispensable requisite of their histories of production. Although at first glance it might seem that architecture is always site-specific, this statement cannot be generalized. Otherwise, some buildings that have been moved would not be the same building anymore: the Pergamon Altar now in the Pergamon Museum in Berlin would not be the Pergamon Altar, for it is not in Pergamon, but in Berlin. This is one difficulty that leads Maurice Lagueux to affirm that architecture is neither autographic nor allographic (Lagueux, 1998). According to him, an architectural work cannot be considered as allographic because "the strictest fidelity to its plans will not be enough to turn a 'reconstruction' of a building into another instance of it" (Lageux 1998, 24). However, it must be considered that an accurate "reconstruction" is possible only if plans are available, i.e., if an allographic system exists; thus, although autographically they are another work, reconstructions can be allographically considered as an instance of a work and this does not invalidate the allographic criterion for identifying architectural works. On the other side, for Lagueux, buildings cannot be autographic

since their identity is not really defined by the historical conditions of their production, unless we consider that the site is in some way included in what Goodman means by the 'historical conditions' of the production of a work of art (Lageux 1998, 24).

In this passage, Lagueux rejects the possibility of including site in the history of production because other autographic works such as paintings are "typically context independent and can be exhibited anywhere in the world without loss of authenticity" (Lagueux 1998, 24). Yet the fact that some autographic works are site-specific, such as the Taj Mahal, does not imply that all other autographic works, such as Rembrandt's Lucretia or Zaha Hadid's Chanel Pavilion, have to be site-specific. Site is a constitutive element of the history of production of an autographic work only if it is considered relevant for establishing the work's identity; and this is not the case of most paintings (and of some buildings). Moreover, even though site is not an indispensable requisite in the history of production of a building, the autographic criterion is still valid for distinguishing between two identical works located on different sites: it is enough to know, for instance, that there is one Cinderella Castle built in 1971 and another in 1983 to discriminate one from the other. And if both 
had been built at exactly the same time, different people would have participated in the construction, for no human being has the gift of ubiquity, and thus their histories of production would continue being different and valid as an identification criterion.

Indeed, as Goodman himself acknowledges, "not every art can be classed as autographic or as allographic. This classification applies only where we have some means of sorting objects or events into works - that is, where there is some criterion for identity of a work" $(M M, 139)$. Yet architecture can indeed be classified according to these two categories, as the several examples discussed here illustrate. Moreover, the affirmation that architecture is neither autographic nor allographic would leave us with no criteria to establish the identity of architectural works. In other words, there would be no manner to conceptually differentiate between an original and a copy, a reproduction, or even a forgery of a building, ${ }^{10}$ and it would be difficult to define the status of another kind of constructions, namely, restorations.

Restorations are another kind of architectural constructions that illustrate the complexity inherent in trying to establish what constitutes the identity of an architectural work. If architecture is considered only as allographic, then a building is restored by following the notational system and by repairing or reconstructing the missing or damaged elements of that building according to the features established in plans. Since, if allographic, its history of production is irrelevant, the restored building has to be taken as another instance of the work. However, in some cases the restorations undertaken in a damaged building are visible. Technically speaking, there are two kinds of restorations: an integral restoration, which intends to repair a work to make the whole look original, and a purist or archeological restoration, which contends that any substitution or addition has to be visible to avoid any pretense of authenticity and, thus, the missing parts are not replaced with pieces indistinguishable from the

${ }^{10}$ According to Goodman, "a forgery of a work of art is an object falsely purporting to have the history of production requisite for the (or an) original of the work" ( $L A$, 122). Although technically complicated, it is not impossible to forge a building, at least an unknown one: by creating a false history of production a temple can be "discovered" in the middle of the jungle, or the plans of an unidentified palace can be "found." 
already existing ones, but clearly discernible from the old ones. ${ }^{11}$ That is to say, since in this latter kind of restoration the distinction between original and newer parts is relevant, some restorations cannot simply be considered as allographic works. However, if architecture is considered as only autographic, then a restoration can be regarded as an alteration of the building, since it implies replacing, adding, and also eliminating some traces of the history of production of the building. Nevertheless, these traces could also disappear through the effect of aging, and the autographic criterion would nonetheless remain valid for determining the identity of the work. Although a restored building would not wholly be like the initial building, it is still the same building as long as the original can be identified as such. ${ }^{12}$

Yet it is not clear if we could still consider a restored building to be the same if, for preservation's sake, each and every one of the original pieces were replaced with new ones. This is similar to the logical paradox raised by the ship of Theseus, whose planks were substituted for new ones when they became damaged until there was no trace left of the original ship and thus posing the question whether it was the same ship or not. As a corollary, one can question what happens if the replaced planks were used to build a second ship. If the stones that constituted a specific building - a church, for instance - were used to build the exact building, we could ask which of the churches, if either, is the original work. If allographic, then both buildings would be instances of the same work. If autographic, then it

${ }^{11}$ For a detailed discussion of these two kinds of restoration and its consequences on the aesthetic experience of a work of art see Mark Sagoff's work (Sagoff 1978, 457-458).

${ }^{12}$ Catherine Z. Elgin argues that, even though the history of production allows the distinction between an original and an exact copy, this does not involve restorations. When referring to paintings she affirms: "The identity of a painting is fixed, Goodman and I contend, by its history of production. A painting is a syntactically dense symbol, and such symbols admit of no replicas. No difference is so small as to be insignificant. Even the closest copy is bound to diverge from the original somewhere. So nothing with a different history can be the same painting. This explains why even the best reproductions are not instances of the paintings they purport to reproduce. It does not, however, tell against restorations. Although every difference between instances constitutes a difference between the symbols they instantiate, it does not follow that every change in an individual instance constitutes a difference in the symbol it instantiates" (Elgin 1997, 106). For the question of identity and restoration see the entire chapter "Restoration and Work Identity" (Elgin 1997, 97-109). 
would be first necessary to determine which elements of the history of production of both buildings are relevant to the work's identity: to consider that the materials make the work the original has as a consequence the fact that only the second church would be the original; to consider that place is relevant leads us to affirm that the complete reconstructed church is the original.

To sum up, Goodman's categories of the autographic and the allographic allow us to establish what constitutes the identity of an architectural work. Although there are some architectural works that can be identified as clearly autographic (such as the Taj Mahal) or clearly allographic (such as the plentiful examples of tract housing), the majority of buildings can be considered from both the autographic and the allographic perspective (as has been shown in the cases of copies and restorations). Thus, not only is architecture as an artistic discipline a "mixed and transitional case" because it simultaneously comprises autographic as well as allographic works, but these two criteria are also intertwined within one and the same building. Both criteria to establish the identity of a work are interlaced insofar as the first stage of the construction process of a building is allographic and the second stage autographic; both criteria are inextricably linked insofar as the two are necessary to identify one and the same building, i.e., the autographic criterion serves to distinguish two identical buildings (such as the two Cinderella Castles), and, at the same time, the allographic criterion allows us to actually build two identical buildings (such as the Cinderella Castle in Orlando and the one in Tokyo). This array of possibilities does not have to be interpreted as a failure in the process of identifying works, but rather as evidence of the inherent complexity and richness of architecture. In other words, the affirmation that architecture is a "mixed and transitional" case is a reflection of the way in which we judge buildings' identities. On the one hand, some buildings are judged according to their history of production; on the other, some buildings are judged taking a notation as the criterion; and sometimes both criteria are used for one and the same building. The cause of this mixture lies not only in the lack of a perfect notation to identify works, but in our reluctance to judge some buildings exclusively from an allographic or an autographic perspective. As discussed in the next section, this hybridism in defining what constitutes the identity of architectural works is paradigmatically illustrated by the case of Mies van der Rohe's Barcelona Pavilion. 


\section{The Barcelona Pavilion: Autographic versus Allographic}

Mies van der Rohe's German Pavilion (now known as Barcelona Pavilion), originally designed as a temporary structure for the 1929 International Exposition in Barcelona and rebuilt in 1986 as a permanent building, is a perfect case for testing Goodman's categories of the autographic and the allographic in architecture. Not by accident, Mies's building is discussed in existing publications on Goodman's criteria for establishing the identity of a work. Gérard Genette takes the Pavilion as an example of a work rebuilt after the demise of its author thanks to the availability of plans, thus acknowledging that the 1929 and the 1986 Pavilion can be (allographically) considered as two instances of the same work. ${ }^{13}$ This opinion is shared by Maurice Lagueux, who affirms that the two Pavilions "constitute two instances of the same work and can be identified allographically." "14 Conversely, Sylvain Malfroy concludes that, using Goodman's categories, the logical status of the 1986 Pavilion is neither that of a copy nor that of an instance of the same work. Rather, according to her, "[w]hile transposing Mies's project, the architects of the 1986 Pavilion have indisputably claimed authorship. There is thus a real interest in distinguishing, in this respect, two Pavilions of Barcelona [...]. The most recent is not a copy, but an original work à propos of a preceding

13 "In contrast, buildings are "always" (as we say) being built or rebuilt from the plans of an allographic architect after his death: take a look, without leaving Barcelona, at Mies van der Rohe's German Pavilion" (Genette 1997, 37). And also: "But the fact that architectural (de)notations exist at least makes it possible to finish a work after the death of its author, like Spreckelsen's Great Arch de La Défense, or, as I have already indicated, to rebuild a demolished building exactly as it was, like the German Pavilion in Barcelona" (Genette 1997, 97).

14 "In this manner, the famous Barcelona Pavilion built by Mies van der Rohe for the International Exposition of 1929, held in the city that gave it its name, was disassembled shortly afterwards - under conditions such that the materials from which it was constructed disappeared mysteriously - but was recently rebuilt on the site in accordance with its architect's plans using similar materials. Here we can state that the 1929 and 1989 [sic] pavilions, which are undoubtedly much more alike than are some interpretations of the same symphony, constitute two instances of the same work and can be identified allographically, even if, when faced with purists upset at not being able to admire Mies's own work, we might hesitate to assure them that these are equivalent instances of the same building” (Lagueux 1998, 21). 
work" (Malfroy 2002, 87). Although Malfroy insists that her position is undeniable, both Genette and Lagueux defend the opposite position, also basing their arguments on Goodman's thought.

In this section I will argue that to consider the 1986 Pavilion simply as a copy does not completely define its identity status. Moreover, to conclude either that the two Pavilions are instances of the same work or that they are two different buildings entails a restriction of the elements that constitute the identity of Mies's work. By analyzing the reconstruction process of the Barcelona Pavilion, I will show how there is a continuous shift between the autographic and the allographic and that neither of them can be eliminated without losing some of the work's constitutive elements. This examination will help to answer whether or not the 1929 and the 1986 Pavilions are the same work.

One of the main arguments in favor of rebuilding the Pavilion was that it was considered a unique work of modern architecture. If we consider that the building that was unique was the 1929 Pavilion, or, using Goodman's terms, that one of the features that make the Pavilion autographic is its uniqueness, i.e., that in this case being autographic follows from uniqueness, then the 1986 Pavilion is a replica of the original one. Architecture is here considered as an autographic art, i.e., the history of production of the building is significant. That is to say, it is precisely the history of production that allows us to distinguish between the original and the replica: even though both Pavilions look the same, we know that they are different because one has a history of production (or construction) that took place under certain conditions in the spring of 1929, and the other has a history of construction under other conditions that took place between 1983 and 1986. That we are able to make this distinction between both buildings, and that we consider the distinction between an original and its replica relevant, brings us to affirm that the Barcelona Pavilion is an autographic work of architecture. This seems to be the general view, particularly because the 1986 building is defined as a reconstruction, and not as the original. Yet the distinction between reconstruction and original is not conclusive enough for determining the identities of the 1929 and the 1986 Pavilions and for incontestably assuming that they are two different buildings, as the following example illustrates.

When the reconstructed Pavilion was dedicated, Georgia van der Rohe, Mies's daughter affirmed that "for a second time, the German Pavilion of Barcelona ha[d] been given to the world" (Amela 1986, 52). Only a work that is not unique can be given "for a second time" and still continue to be 
the same; only allographic works can be reproduced and maintain the same identity. This compels us to affirm that the building recovered in 1986 is the same as the one erected in 1929, i.e., that the world has been given back the "German Pavilion of Barcelona," assuming that what has been recovered is the same as what had been lost in 1930 due to its dismantling. In this context, the autographic distinction between original and replica is meaningless, because a unique and original work - a work of which there is only one - cannot be given twice. In other words, the Pavilion "can be lived in today for a second time" (Amela 1986, 52) only if it is interpreted and judged as an allographic work. Here we find a first oscillation between autographic and allographic criteria; a closer look at the process of reconstruction will show how this shifting is continuous, in other words, how autographic and allographic features are inextricably interwoven when trying to determine the identity of the Barcelona Pavilion.

The main obstacle faced by Solà-Morales, Cirici, and Ramos, the architects responsible for the reconstruction of Mies's Pavilion, was the absence of reliable and definitive plans, for the originals were lost. ${ }^{15} \mathrm{In}$ their words: "One thing that has been a constant problem in recreating the scheme for the German Pavilion in Barcelona is precisely its nonexistence" (Solà-Morales 1993, 9). Thus the first step was to fix its identity by means of a notational system, i.e., new plans, cross sections, and elevations. Although the autographic character of the Pavilion is what allows us to distinguish between the two buildings, to build the 1986 Pavilion the criterion followed was not the history of production of the building, but the recreation of a "scheme." Moreover, it is literally impossible to reproduce the history of production of the 1929 Pavilion to build the 1986 one and, therefore, the only possible way to rebuild the Pavilion is by developing a series of plans. In other words, the identity of the Barcelona Pavilion is established by allographic processes, i.e., by the creation of a notation. Goodman expresses this idea as follows:

[W]hile availability of a notation is usually what establishes an art as allographic, mere availability of a notation is neither a necessary nor a sufficient condition. What is necessary is that identification of the or an instance of a work be

15 Since its dismantling in January 1930, there have been several attempts to reconstruct the Pavilion. In 1957, Mies offered to redraw the plans, for "[t]he original construction drawings of the Pavilion were lost or misplaced in Germany" (Cirici 1983, 6), as Mies himself wrote to the then promoter of the Pavilion's reconstruction. For a summary of the reconstruction attempts see (Solà-Morales 1993, 26-27) and (Capdevila 2007, 40-42). 
independent of the history of production; a notation as much codifies as creates such an independent criterion $(M M, 139)$.

This is precisely the case of the Barcelona Pavilion. Although a notational system that uniquely determined the work was not available, it was possible to identify the work without relying on the history of its construction, and the work of Solà-Morales and colleagues was to create an allographic criterion. Thus the Pavilion is here rather allographic than autographic, because it is actually possible to create a notation and because the history of its construction is not decisive to fix its identity. Nevertheless, the process of allographically establishing the identity of the Pavilion was open-ended. The architects found themselves "faced with the singular circumstance of a task of reconstruction for which there was an abundance of information relating to what we were to rebuild, yet not enough to establish, beyond all doubt, the characteristics belonging to Mies's mythic building" (Solà-Morales 1993, 5). The impossibility to completely fix the Pavilion's identity lies in the fact that not all the available sources provided the same information and thus could not be relied on.

It could be argued that this degree of uncertainty, even if minimal, invalidates the possibility of establishing the identity of Mies's work in an allographic way. However, the fact that it is not possible to exactly determine each and every one of the features that constituted the 1929 building does not mean that we cannot establish its identity by means of a notation, for some of the properties are irrelevant when establishing identity. A notation - a score, a script, an architectural plan - is abstract and "defines a work solely in terms of its necessary features, even if its contingent features are legion" (Genette 1997, 19). In other words, idiosyncratic attributes are excluded from notation and only unrenounceable properties are allographically fixed. Parallel cases in other arts, in which similar processes are undertaken to establish the identity of the work and whose validity is not questioned, reveal that uncertainty is not an impediment to define an architectural work by means of a plan: critical editions of literary works compare several versions of the same work and, in case of conflict, one of them (or a specific passage) is established as the canonical one. Much the same occurs when there are several versions of a musical score and the identity of the piece is established by fixing a unique score.

New plans, elevations for each façade, and various sections and details of the Pavilion were developed, specifying several features that had not 
been defined in previous plans, and thus fixing what would constitute its identity in an unprecedented way. From that moment, following Goodman's theory, only the building that fulfills the conditions established by these notational systems can be considered the Barcelona Pavilion. The architects responsible for the 1986 Pavilion described their main reconstruction criterion as follows:

[A]n undisputed premise here was the concept of a reconstruction that would interpret as faithfully as possible the idea and the material form of the 1929 Pavilion. If we have made a distinction between idea and material form, it is because the study of the materials used in the project, alongside other contemporary schemes by its architect, indicates that the physical execution of the building, for reasons of economy, haste or simple technological limitations, did not always come up to the level of its ideal character before, during and after construction (SolàMorales 1993, 29).

Here Goodman's terms prompt us to consider that the Pavilion is allographic; the "ideal character" of the work would correspond to a work whose features are completely established by a notation, and the "material form" would be an actual built instance of this work. Yet, according to this premise, the 1929 Pavilion would not be a perfect version of the Barcelona Pavilion: it is known, for instance, that due to the scarcity of green marble and travertine, some walls were made out of brick and painted green and yellow (Solà-Morales 1993, 14). That is to say, the built 1929 Pavilion was an approximation of what it actually should have been; a building that apparently was the Barcelona Pavilion, but did not possess some of its properties. Strictly speaking, hence, the 1929 Pavilion cannot be considered as an instance of the Barcelona Pavilion as planned by Mies, for the "physical execution of the building" does not "come up to the level of its ideal character," as noted by Solà-Morales, Cirici, and Ramos. Obviously, one is very reluctant to affirm that the Pavilion built in 1929 is not the actual Barcelona Pavilion, and that the 1986 building is indeed an instance of the Pavilion, or, more precisely, the first and only instance of the Pavilion, because it accurately fulfills the requirements established by the notational system to be considered an instance of the work. As a matter of fact, this is literally the aim the reconstruction had - to complete the uncompleted 1929 work. ${ }^{16}$

\footnotetext{
16 "It should be noted that it was our firm decision to totally clad all three faces of this wall, although we were well aware that on the 1929 building two of the exterior wall surfaces were without the green marble, which was replaced by a simple rendering in the same tone as the stone. In this respect, too, we were perfectly clear
} 
Even if, according to the architects responsible for the reconstruction, the 1986 building is more the Barcelona Pavilion (and the 1929 Pavilion less), our intuitive reluctance to conclude that the 1929 Pavilion is not the Barcelona Pavilion - that the original Pavilion is actually not the Pavilion designed by Mies and built under his direction in 1929 because it was "not completed" - points to the need to shift the chosen identity criterion again, from allographic to autographic. In other words, this leads us to question the way in which the identity of the Barcelona Pavilion had been established by Solà-Morales, Cirici, and Ramos. Their premise when reconstructing Mies's work was to fulfill the Pavilion's "ideal character" fixed by them in a notation even though this would exclude the 1929 Pavilion from being an instance of the work. This means that their plan fixed as constitutive elements of the work some characteristics that the 1929 Pavilion did not fulfill. Nevertheless, a notation, or plan in this case, does not necessarily have to fix the "ideal," but only determine the constitutive elements of a work. It is perfectly possible to design a plan that establishes the identity of both the 1929 and the 1986 Pavilions. That is to say (and returning to Goodman's categories), the fact that the 1929 Pavilion does not fulfill the requirements established by a certain plan does not mean that the Barcelona Pavilion cannot be considered as an allographic work.

Another shift from allographic to autographic identity processes is necessary at this point. To elude the counterintuitive statement that the 1929 Pavilion is not the Barcelona Pavilion, it should be taken into account that the Barcelona Pavilion is not completely allographic, i.e., that its identity is not totally defined by a plan. While scores and scripts seem to be sufficient in fixing the identity of musical pieces and plays, and we consider that the differences among instances do not matter for establishing their identity, this seems not to be the case of architectural plans, for extranotational information (referring to the construction materials, for instance) is required to absolutely determine a building. It can be argued that the extranotational information is required because the notation in architecture is not accurate enough to completely establish the identity of a certain building, as Goodman also maintains ( $L A, 221)$. Nevertheless, it should be considered whether the extranotational information is necessary

that our criterion was not to reproduce the building as it had actually been when it was completed - or not completed - in 1929, but to carry through to its conclusion an idea with regard to which we had an abundance of information and the support of an architectural logic that was beyond all doubt (Solà-Morales 1993, 32). 
to determine the identity of a work because some features that constitute its identity are not able to be allographically fixed. That is to say, even if we had a perfect notation, a specific work could also be determined by autographic features, and then its identity would still be a mixed case of allographic and autographic characteristics. Actually, this is the case of the Barcelona Pavilion: on the one hand, we distinguish between original and replica through the different histories of constructions - autographically; and, on the other, the reconstruction was possible by means of the creation of a notational system - allographically. Thus Goodman's statement about architecture being a transitional case is incorrect: architecture is not a "mixed and transitional case" $(L A, 221)$. It is a mixed but not transitional case.

Let us suppose that we would consider the Barcelona Pavilion only as an allographic work, i.e., that we would establish its identity based only on a notation. Then, not only would the 1929 and the 1986 Pavilion be considered instances of the work, but so would every building that fulfilled the requirements established by the plan. Consequently, if the specific location of the Pavilion is not determined by its notation, it would be possible to have an indeterminate number of Barcelona Pavilions spread around the world. Yet it can also be argued that the location of the Pavilion can be fixed by a notation by including its latitude, longitude, and orientation in a plan. In this way, only one building at a time would be able to fulfill the requirements allographically established. Thus, only the 1929 and the 1986 Pavilion - and not any other Pavilion built in any other place - would be instances of the Barcelona Pavilion. This would mean that the Pavilion is an allographic work with two instances (1929 and 1986) provided, of course, that the 1929 Pavilion is an actual instance of the Pavilion, which, as has been discussed above, is questionable depending on the notation or notations (plans, elevations, and sections) used to establish its identity. Even if it is possible to consider that the Barcelona Pavilion is only allographic, this does not seem to be completely adequate: even if it is technically possible to endlessly reproduce the Barcelona Pavilion following a plan, its site-specificity limits this allographic potential. Considering this, then Goodman's argument, according to which the Pavilion is not completely allographic because "its notational language has not yet acquired full authority to divorce identity of work in all cases from particular production" ( $L A, 221)$, is not quite right. The Pavilion is autographic because intrinsic autographic features preclude its being a completely allographic work; even if a perfect notation were available, the 
Pavilion would still be partly autographic. This resistance to becoming completely allographic is a reflection of the values that prevail when we classify works as autographic or allographic. That is to say, if we are reluctant to consider the Pavilion completely allographic, it is because an important element of its identity would be lost; the Pavilion has indelible autographic features that limit its allographic characteristics.

As has been shown, site is one of the elements that can tip the balance in favor of considering that the Pavilion is autographic. Indeed, that site was one of the Pavilion's constitutive elements was a given for the architects responsible for the reconstruction: as Solà-Morales affirmed during the dedication ceremony, the Pavilion "should not and could not be in any other place" (Amela 1986, 52). However, not everybody agrees that the Pavilion is site-specific; instead, some consider it a "prototype; a perfect, autonomous spatial experiment capable of being considered as an object" (Solà-Morales 1993, 28). Thus, the Barcelona Pavilion can be regarded as both site-specific and not site-specific. Considering the Pavilion as not sitespecific makes of it an allographic building reproducible everywhere (because its identity is determined by a notation that does not define its location). However, the fact of being site-specific does not make it immediately autographic (for site-specificity is not a necessary condition for a work to be autographic). If the Barcelona Pavilion is taken to be autographic, it is because its location has been considered a constitutive element of its identity, i.e., a relevant feature in the history of its construction. Consequently, the 1986 Pavilion is only a replica, or, more concretely, the only possible replica.

However, this is not the Pavilion's definite status, for another shift in the identity criteria is possible. It can be argued that the Barcelona Pavilion is autographic and that its ephemeral character is a constitutive element of the history of its production, because Mies designed it taking into account that it would stand only nine months. The 1986 Pavilion would then be, if it were only autographic, a partial reproduction of the 1929 Pavilion because it ignores the ephemeral character of the original having lasted (as of this writing) twenty-one years longer. Since this ephemeral character is not respected in the reproduction, either the durability of the Pavilion is not a constitutive element of the history of its construction - which seems difficult to maintain given the circumstances for which it was built - or the Pavilion is rather allographic than autographic - which is actually one of the underlying and implicit conditions for the Pavilion to be rebuilt, 
because the possibility of creating a notation is what allowed the reconstruction.

After having discussed the main elements of the Pavilion's reconstruction process, it seems that the initial question, whether the 1929 Pavilion and the 1986 Pavilion are the same or not, does not have a univocal answer. In Goodman's terms, the Pavilion is both autographic and allographic: it is autographic, considering the history of its production (and then the work we can visit now is a replica), and allographic, considering its notation (and the present work is the 1986 instance of it). As has been shown, the two criteria to establish what constitutes the identity of a work (history of production and notation) are both pertinent for determining the identity of the Barcelona Pavilion. More than that, they are inseparable, for arguing that the Pavilion is only autographic or only allographic does not lead to convincing conclusions. Maintaining that the Barcelona Pavilion is only autographic ignores the fact that the identity of Mies's work can be established by a notation. Arguing that the Pavilion is only allographic could lead to the conclusion that the 1929 Pavilion itself is not the Barcelona Pavilion at all (if its notation fixes as relevant features the 1929 Pavilion did not possess). The Pavilion clearly has both autographic and allographic characteristics. Since we are reluctant to admit that the 1929 Pavilion is not an instance of the work and, rather, we consider it as the original, the Barcelona Pavilion is an autographic work and, consequently, the 1986 Pavilion is a reproduction. Nevertheless, since there exists the possibility to create a notation to fix its identity (and it has actually been created), the Barcelona Pavilion is allographic and the 1986 Pavilion is an instance of it. Yet not all the features of the Pavilion, such as site and materials, can indisputably be established by means of a notation: this makes the Pavilion more autographic than allographic - of course, only if these features are considered to be constitutive for the Pavilion. Furthermore, even though these features would be established by a plan, it would be possible to change them and the work continue to be considered the same, which is what actually happened: Mies decided to use brick instead of marble on some of the exterior walls and thus violated the initial project, but the Barcelona Pavilion continued being the Barcelona Pavilion. Taking this fact into account, the Pavilion is autographic rather than allographic.

According to Goodman, "[ $\mathrm{t}]$ he allographic art has won its emancipation not by proclamation but by notation" $(L A, 122)$. After challenging the notions of autographic and allographic with the case of the Barcelona 
Pavilion, we should specify and affirm that notation is a necessary condition for architecture to achieve "full authority to divorce identity of work in all cases from particular production," but not a sufficient one ( $L A$, 221). Apart from a precise and accurate notation, it is necessary that the difference between two architectural works based on the same plan be considered irrelevant, and this is (still) not the case in the Barcelona Pavilion: the distinction between original and reproduction matters. Although the Barcelona Pavilion could be a completely allographic work, it is a hybrid: it is a mixed work of architecture whose identity is established by autographic and allographic features - neither reducible to the other.

\section{Conclusion}

Determining the identity of the Barcelona Pavilion or any other architectural structure is an initial and indispensable step in construing the meaning of architecture, since both our understanding and experience of an architectural work change depending on whether or not we know that the work that we are contemplating is authentic. Furthermore, if, like Goodman, we grant aesthetics and artistic understanding a preeminent role in our comprehension and acknowledge that our construals actually construct worlds, then it is crucial to examine the conceptual elements that actively participate in these constructions, especially those referring to identity. Establishing what constitutes the identity of buildings, determining whether an architectural structure is original or not, and providing criteria to undertake these tasks are also constitutive in the creation of a work and its world.

As has been shown, the case of architecture is particularly complex because of the intrinsic features of this discipline. Goodman's statement that "insofar as its notational language has not yet acquired full authority to divorce identity of work in all cases from particular production, architecture is a mixed and transitional case" ( $L A, 221)$ has to be understood as a reflection of the current judgments concerning the identity of architecture. While it is certainly true that architecture is a mixed case, i.e., that the autographic and the allographic coexist as criteria to identify a work, the affirmation that architecture is transitional needs to be reconsidered. Goodman's prediction, according to which architecture will become completely allographic once a notational system that completely identifies a work is achieved, does not have as a necessary consequence 
that the work's identity will be independent from its history of production. In other words, the autographic criterion for identifying works still concerns contemporary buildings with an accurate notation that fulfills its function of fixing the work's identity. Thus, the distinction between autographic and allographic is not related to an intrinsic historical development of architecture, a process which would bring us to affirm (with Goodman) that architecture is currently a transitional case. Nevertheless, it must be noted that architecture could only become allographic with the establishment of plans, which is indeed a historical process. Furthermore, since architecture is a discipline continuously evolving, it cannot be definitively excluded that, in the future, the allographic criterion will be enough for identifying architectural works. That is to say, it is uncertain whether or not the autographic features will cease being considered as constitutive elements of a work's identity and, in that way, when establishing the identity of a work, no loss of any fundamental property would be experienced. Since works of architecture incessantly age, change, and evolve, we are immersed in a never-ending process of construing and constructing architecture. ${ }^{17}$

\section{References}

Amela, V. (1986): “Inaugurado en Barcelona el pabellón alemán de Mies van der Rohe con la presencia de su hija" in: La Vanguardia: Barcelona, 3 June 1986, 52.

Capdevila, R. (2007): Construing Reconstruction: the Barcelona Pavilion and Nelson Goodman's Aesthetic Philosophy (SMArchS Thesis), Cambridge, MA: Massachusetts Institute of Technology, 2007.

Cirici, C.; Ramos, F.; Solà-Morales, I.; (1983): "Proyecto de reconstrucción del Pabellón Alemán de la Exposición Internacional de Barcelona de 1929” in: Arquitecturas bis 44 (1983), 6-17.

Elgin, C.Z. (1997): "Restoration and Work Identity", in: Elgin, C.Z.: Between the Absolute and the Arbitrary, Ithaca: Cornell University Press, 1997, 97-109.

Fisher, S. (2000): “Architectural Notation and Computer Aided Design" in: The Journal of Aesthetics and Art Criticism 58 (2000), 273-289.

${ }^{17}$ This article is an abridged version of my master thesis (Capdevila 2007). I am thankful to Catherine Z. Elgin for her comments and suggestions. 
Genette, G. (1997): The Work of Art. Immanence and Transcendence, Ithaca: Cornell University Press, 1997.

Kivy, P. (2000): "How to Forge a Musical Work", in: The Journal of Aesthetics and Art Criticism 58 (2000), 233-235.

Kivy, P. (2002): "Versions and "Versions," Forgeries and "Forgeries": A Response to Kirk Pillow", in: The Journal of Aesthetics and Art Criticism 60 (2002), 180-182.

Lagueux, M. (1998): "Nelson Goodman and Architecture", in: Assemblage 35 (1998), 18-35.

Malfroy, S. (2002): "Combien y a-t-il de Pavillons de Barcelone? Réflexion sur le statut logique de la "réplique" in situ d'un édifice détruit", in: Matières 5 (2002), 76-89.

Pillow, K. (2002): "Versions and Forgeries: A Response to Kivy", in: The Journal of Aesthetics and Art Criticism 60 (2002), 177-179.

Pillow, K. (2003): "Did Goodman's distinction survive LeWitt?", in: The Journal of Aesthetics and art Criticism 61 (2003), 365-380.

Sagoff, M. (1978): "On Restoring and Reproducing Art" in: The Journal of Philosophy 75 (1978), 453-470.

Solà-Morales, I.; Cirici, C.; Ramos, F. (1993): Mies van der Rohe: Barcelona Pavilion, Barcelona: Gustavo Gili, 1993.

Weemans, M. (2001): "Pratiques allographiques et reproduction: Sol LeWitt, Claude Rutault, Lawrence Weiner", in: Goudinoux, V.; Weemans, M. (eds): Reproductibilité et irreproductibilité de l'oeuvre d'art, Bruxelles: Ante, 2001, 136-165. 
